\title{
VIOLENCIA CONTRA LAS MUJERES Y FEMICIDIO
}

\section{VIOLENCE AGAINST WOMEN AND FEMICIDE}

\author{
MSc. Marcela Piedra Durán \\ Universidad de Costa Rica \\ San José, Costa Rica \\ marcela.piedraduran@ucr.ac.cr
}

Costarricense. Politóloga. Profesora de la Universidad de Costa Rica. Cuenta con una Maestría Académica del postgrado centroamericano de Ciencias Políticas de la Universidad de Costa Rica, Licenciada en Ciencias Políticas con énfasis en Gobierno y Políticas Públicas de la misma casa de estudios. Consultora independiente para la Fundación para el Desarrollo Local y el Fortalecimiento Municipal (DEMUCA), Fundación para la Paz y la Democracia (FUNPADEM), Fundación Friedrich Ebert, Programa para la Cohesión Social en América Latina (EUROsociAL) y Programa de las Naciones Unidas para el Desarrollo (PNUD) en temas de género, seguridad ciudadana, prevención de la violencia, democracia y ciudadanía. Fue coordinadora del Área de Ciudadanía Activa, Liderazgo y Gestión Local, a cargo del Centro de Formación Política de la Mujeres y Profesional Especialista del Área de Gestión de Políticas Públicas para la Equidad de Género del Instituto Nacional de las Mujeres (INAMU). Actualmente se desempeña como profesora de la Escuela de Ciencias Políticas e investigadora del Centro de Investigación y Estudios Políticos (CIEP) y del Programa de Interés Institucional en Violencia y Sociedad, es conductora del programa de análisis político Sobre la Mesa una coproducción del CIEP y el Canal UCR, todas instancias de la Universidad de Costa Rica. Especialista en género y diversidad de la Oficina de las Naciones Unidas de Servicios para Proyectos (UNOPS). Sus líneas de investigación son género, feminismos, seguridad ciudadana, prevención de la violencia, democracia y ciudadanía.

Recibido 21/01/2020 - Aceptado 20/04/2020

\section{RESUMEN}

Este artículo es producto del proyecto de investigación "El femicidio: la máxima expresión de la violencia contra las mujeres", tiene como objetivo visibilizar la violencia contra las mujeres y el femicidio como resultado de las desigualdades de poder generadas y legitimadas por las estructuras patriarcales. Es resultado de la recopilación de información teórica y estadística, que demuestran la importancia del análisis del femicidio como un asunto de interés público y la 
necesidad de ser incorporado de manera integral en todas las políticas de prevención de la violencia que se desarrollen en Costa Rica.

Palabras clave: violencia, patriarcado, discriminación contra las mujeres, misoginia, femicidio

\section{ABSTRACT}

This article is a result of the findings of the research project "Femicide: The Extreme Expression of Violence Against Women". It's objective is to expose the violence against women and femicide as a result of the power inequalities generated and legitimized by patriarchal structures The theoretical discussion about the concept of femicide and how it is reflected in the country's statistics not only highlight the femicide as a public interest matter, but also the need to include it in all the violence prevention policies developed in Costa Rica.

Keywords: violence, patriarchy, discrimination against women, misogyny, femicide.

\section{INTRODUCCIÓN}

Para iniciar la reflexión sobre la violencia contra las mujeres y el femicidio como su máxima expresión, tal y como lo plantea Samara de las Heras (2009), debemos tomar como puntos de partida no solo el redescubrimiento de la historia de las mujeres, de las reivindicaciones y logros obtenidos a lo largo del tiempo, sino de su situación en la sociedad, porque el primer paso para erradicar el sistema de sumisión y obediencia que las subyuga, es tomar conciencia de cómo se produce y cómo las afecta para, posteriormente, definir la estrategia para erradicarlo.

El patriarcado es la manifestación e institucionalización del dominio masculino sobre las mujeres, niños y niñas en la familia, dominio que se extiende a todos los espacios sociales; es una toma de poder histórica por parte de los hombres sobre las mujeres, cuyo mecanismo legitimador es el orden biológico, pero elevado a la categoría política y económica.

Para Alda Facio y Lorena Fries (1999) este pensamiento dicotómico, jerarquizado y sexualizado, divide todo en hechos de la naturaleza o de la cultura, al situar al hombre y lo masculino bajo la segunda categoría, y a la mujer y lo femenino bajo la primera, erige al hombre en parámetro o paradigma de lo humano, al tiempo que justifica la subordinación de las mujeres en función de sus pretendidos "roles naturales".

La sociedad patriarcal ha instaurado una dinámica de subordinación, que se percibe como normal y que, además, establece formas de relación que devienen 
del deber ser/hacer del comportamiento individual y las estructuras sociales, Janet Saltzman (1992) indica que se expresa en:

- Una ideología de la discriminación contra las mujeres, sin importar la etnia, clase social, orientación sexual, regiones, tipos de familia, entre muchas otras diferencias; todas las mujeres comparten una historia de exclusión y el no poder ejercer ciertos derechos.

- El lenguaje que abiertamente desvaloriza a las mujeres, sus roles, sus labores, sus productos y su entorno social, menos prestigio y/o poder que el que se les da a los hombres.

- Significados negativos atribuidos a las mujeres y sus actividades a través de hechos simbólicos o mitos, que no siempre se expresan de forma explícita.

- Estructuras que excluyen a las mujeres de la participación o el contacto con los espacios de poder, los hombres tienen el dominio en todas las instituciones importantes de la sociedad, en lo económico, lo político y lo cultural.

El dominio de los hombres sobre las mujeres tiene lugar mediante un mecanismo doble, el control de las funciones sexuales y reproductoras, que se refuerza al restringir el ámbito de las tareas productivas al que tiene acceso y, a su vez, la prohibición de las tareas que se le imponen a las mujeres queda reforzadas por el hecho de que están controladas por su inserción en las estructuras del parentesco (Rubin,1986).

John Stuart Mill (citado por Amorós, 2005) afirmó que los grupos oprimidos expresan sus resentimientos por los abusos del poder que sufren antes de cuestionarse las bases mismas de la legitimidad de este poder, en esta lógica, la desigualdad y la violencia contra las mujeres se ha sustentado en argumentos de autoridad, tradición, normalización, costumbre, pero es poco cuestionada la estructura patriarcal misma; es decir, se explica desde lo cultural, pero no se aborda lo estructural y como esto tiene implicaciones directas en un ejercicio violento del poder contra las mujeres en todas las esfera de la vida.

El referente teórico del concepto más elemental de poder es lo que denominó Max Weber Herrshaft, es decir, "relación de dominio y subordinación" (Amorós, 2005), en este sentido, el sistema patriarcal, ejerce este poder por medio de la diferenciación de género que ordena:

- La sexualidad, es decir, el intercambio erótico y la posibilidad de acceso sexual.

- La reproducción humana.

- La división sexual del trabajo.

- Todas las relaciones sociales. 
Esta diferenciación de género se manifieste en el plano estructural (división sexual del trabajo), institucional (en relación con las normas que distribuyen los recursos) y simbólico (relacionado con los valores y atributos que se asignan socialmente a lo masculino y a lo femenino). Bourdieu plantea que el orden de las cosas no es un orden natural, sino que es una construcción social, una visión del mundo con la que el hombre satisface su sed de dominio, visión asumida por las propias mujeres, aceptando su subordinación (Bordieu, 2000).

El patriarcado gravita, afirma Kate Millet (citada por Amorós, 2005), alrededor de la institución de la familia, que es, simultáneamente, un espejo de la sociedad y un lazo de unión con ella; en otras palabras, constituye una unidad patriarcal dentro del conjunto del patriarcado, que produce y reproduce la relación de dominio y subordinación sobre las mujeres. Perla Haimovich indica que es en el espacio doméstico (privado) donde el hombre puede ejercer poder sobre sus posesiones legítimas, la mujer, niños y niñas (Haimovich, 1990)

Esta institución es, además, funcional al Estado de las sociedades patriarcales, que se relacionan con la ciudadanía a través de los cabezas de familia (principio de legitimidad), de hecho el triunfo patriarcal es producto de la diferenciación y antagonismo social, la separación entre vida pública y privada y el predominio de las formas verticales y autoritarias dentro de las familias, que favorecieron a los hombres para que se apropiaran del excedente social de producción, cuya protección y trasmisión fue sancionado a través de mecanismos institucionales, tales como la familia y el matrimonio, lo que posibilitó la estructuración de relaciones de desigualdad y opresión hacia las mujeres, colocándolas en el ámbito exclusivo de los doméstico (Valenzuela, 2012).

La violencia contra las mujeres resulta inherente al orden patriarcal y su violencia simbólica, que consiste en "(...) un mecanismo de dominación y control creador de poderes jerárquicos (poderes simbólicos) que se basan en la eficacia y los efectos de las inclinaciones modeladas por las estructuras de dominación que las producen” (Bourdieu, 2000, p. 58).

En este sentido, la violencia estructural o simbólica "se basa en jerarquías y desigualdades de diferentes índoles que estimulan la opresión de las mujeres, tanto en el ámbito privado como el público" (Piedra y Esquivel, 2012, p.21); lo que genera un fuerte impacto en la vida de las mujeres, ello principalmente porque se ven expuestas a un ambiente latente cargado de "castigos, mandatos, negociaciones y limitaciones de orden arbitrario" (Aguilar, 2002, p. 189), que condicionan la capacidad de reacción de las mujeres ante situaciones de dominación, aunado a la legitimación de esquemas sociales en los que se establecen roles diferenciados de poder entre el hombre y la mujer; siendo esta situación el ejemplo más claro de la violencia simbólica, debido a que establece un orden lógico del mundo que se moldea a partir de lo masculino y recae como condicionante de lo femenino (Bourdieu, 2000). 
La violencia simbólica de género se diferencia de la violencia simbólica general mediante la dinámica de subordinación que aparece como normal y que, además, establece formas de relación que devienen del deber ser/hacer del comportamiento individual y las estructuras sociales (Aguilar, 2002).

Como bien lo plantea José Manuel Valenzuela (2012) la expresión límite de la violencia contra las mujeres es el femicidio, las mujeres asesinadas denotan estructuraciones de género definidas por las desigualdades de poder, es una violencia anclada en las estructuras patriarcales, con altos índices de impunidad, donde las mujeres pueden ser sacrificadas, ya que se encuentran en mayores condiciones de vulnerabilidad e indefensión.

Marcela Lagarde indica que el femicidio expresa un orden patriarcal que funciona como mecanismo estructurante de la desigualdad entre mujeres y hombres, un sistema de clasificación social y sistema sexo-género reproductor de la inequidad de poder en todos los ámbitos (social, político, económico y cultural). El femicidio, precisamente, es producto de esas condiciones estructurales de la organización social de los géneros y la dominación de los hombres, que tienen como mecanismo reproductor de la opresión de las mujeres la violencia de género (Lagarde, 2008).

Las relaciones patriarcales por sí mismas implican diversas formas de violencia, puede ser patrimonial, física, emocional y psicológica. Como elementos del orden patriarcal el femicidio es la dimensión extrema de esta violencia, la expresión límite de la misoginia (Russell y Harmes, 2006).

El uso del concepto femicidio ${ }^{1}$ tiene una intencionalidad política, hacer visible el sustrato sexista o misógino de estos crímenes, que permanece oculto cuando se hace referencia a estos a través de palabra neutras como homicidio (Toledo, 2009). Tanto la violación como el femicidio son las formas más extremas de terrorismo sexista, perpetrados por esposos, amantes, padres, conocidos o extraños, contra mujeres, de ahí la importancia de reflejar esta compresión política (Caputti y Russell,1992).

\section{VIOLENCIA DE GÉNERO}

Las mujeres están expuestas a ser víctimas de femicidio y de hechos violentos, en contextos, estrechamente ligados a la violencia intrafamiliar y doméstica. Según Ana Hidalgo, el femicidio es la principal causa de muerte violenta intencional de mujeres en Costa Rica y, además, "la cuota principal de los femicidios lo aporta la violencia de pareja o intrafamiliar (...)" (p 67-68), que para el periodo 2007-2017 representa en promedio un 75\%, según el análisis de

\footnotetext{
${ }^{1}$ En Costa Rica la normativa nacional utiliza el término femicidio, traducción literal del concepto acuñado por Diana Russell femicide, que va a ser utilizado en el presente artículo, aunque otras autoras, como Marcela Lagarde utilicen el concepto de feminicidio, como una forma de hacer visible la variable impunidad, muchas veces presente en este tipo de delitos.
} 
los datos del Observatorio de Violencia de Género contra las Mujeres del Poder Judicial.

La violencia de género se define como "todo acto de violencia basado en el género, cuyo resultado posible o real es un daño físico, sexual o psicológico, incluidas las amenazas, la coerción o la privación arbitraria de la libertad, ya sea que ocurra en la vida pública o en la privada [...] es ante todo una imposición arbitraria que tiene como efecto práctico la subordinación, así como imposición de conductas, discursos, valores, normas, comportamientos, roles y, sobre todo, de las representaciones simbólico culturales ${ }^{2}$ masculinas/masculinizantes" (Aguilar, 2002, p.157).

La violencia de género se puede manifestar a través de la coacción, cuando se intenta obligar o impedir a la mujer hacer algo, ya sea mediante una forma de chantaje o una actuación determinada (privarla de determinadas relaciones o vínculos con amistades o familiares, obligarla a mantener relaciones sexuales ejerciendo la fuerza física o cualquier otro tipo de coacción, obligarla a ejercer la prostitución o a guardar silencio para encubrir los malos tratos de que es objeto). Además, se expresa como violencia psicológica, cuando se trata de perturbar y denigrar la imagen y la autoestima de la mujer ante el entorno social, ya sea mediante el empleo de insultos y/o comportamientos que la humillen indistintamente de si es en un lugar público o privado (cuando el agresor le impide hablar u opinar, cuando subestima o ridiculiza sus opiniones, aspecto o comportamiento, le impide disponer de un patrimonio común o le exige detalles de sus actos u omisiones) (Piedra y Esquivel, 2012).

Asimismo, en el marco de la Convención Interamericana para Prevenir, Sancionar y Erradicar la Violencia contra la Mujer, más conocida como la Convención de Belem do Pará ${ }^{3}$, se identifica a la violencia contra las mujeres como una ofensa a la dignidad humana, una manifestación de las relaciones de poder históricamente desiguales entre mujeres y hombres, que trasciende todos los sectores de la sociedad, independientemente de su clase, etnia, edad, religión, entre otros; por lo cual, su eliminación es condición indispensable para el desarrollo integral de las mujeres en todas las esferas de la vida.

En lo referente a la violencia en contra de las mujeres, el artículo 1 de la Convención de Belem do Pará, define la violencia como "cualquier acción o conducta, basada en su género, que cause muerte, daño o sufrimiento físico, sexual o psicológico a la mujer, tanto en el ámbito público como en el privado". En este sentido, es posible establecer una escala de violencia, en la que, en el

\footnotetext{
${ }^{2}$ Los "poderes simbólicos" se basan en la eficacia y los efectos de las "inclinaciones modeladas por las estructuras de dominación que las producen" (Bourdieu, 2000: 58). Estos poderes simbólicos producen disposiciones jerárquicas que favorecen la inclusión o exclusión de las personas de los diferentes ámbitos (sociales, culturales, etc.) y de todo tipo de relaciones (Aguilar, 2002)

${ }^{3}$ Denominada así por su celebración en la ciudad de Belem do Pará en Brasil, en junio de 1984 
nivel superior, se encuentran los femicidios como la máxima expresión de esa violencia.

Ante este panorama y ante la predominancia histórica del modelo de organización social patriarcal, Piedra y Esquivel (2012) mencionan los mecanismos mediante los cuales se ha invisibilizado y se invisibiliza la violencia en contra de las mujeres, los cuales refieren a Rainero et al (2006):

1. La culpabilidad y responsabilidad adjudicada a las mujeres por las conductas agresivas de las que son objeto ("usted se lo buscó"): la responsabilidad de la violencia de la que son víctimas recae en las mujeres, en lo que hicieron o dejaron de hacer y no en el agresor.

2. El desconocimiento de las experiencias de violencia cotidiana vividas por las mujeres: refiere fundamentalmente, a una concepción de la violencia centrada en las agresiones físicas con consecuencias en el cuerpo de las víctimas, lo cual ignora el irrespeto de derechos e intimidación como una violencia que afecta la vida cotidiana y el desconociendo o "normalización" de la violencia sexual hacia las mujeres. El acoso callejero es un claro ejemplo de esto, ya que lesiona la integridad física, psicológica y sexual de las mujeres que se sienten violentadas por palabras, gestos, tocamientos e incluso abuso sexual o intentos de violación al hacer uso de espacios públicos como calles, parques, transporte público, centros comerciales, estadios, entre otros.

3. La relativización del daño y las consecuencias en la vida de las mujeres: el desconocimiento de algunas formas de violencia implica, a su vez, la invisibilización o subestimación de sus consecuencias en la cotidianeidad y proyectos de vida de las mujeres. Una forma en que se manifiesta es la ridiculización de la situación que se expresa en chistes y bromas. Un ejemplo claro es la relativización, cuando a la hora de comentar o evaluar una situación de violencia que ha vivido una mujer, se escuchan frases como "no fue grave... no la violó" o "no le hicieron nada, no pasó nada... no perdió la vida"; o cuando se caracterizan a los agresores que ejercen estas acciones intimidatorias contra las mujeres, como "chistosos" y no como violentos.

4. La patologización de la violencia: una forma de invisibilizar es adjudicar problemas de orden psicopatológico a aquellos varones que violan o realizan algún acto de agresión sexual, inclusive el exhibicionismo. La consideración de la violencia como un fenómeno individual y psicopatológico califica al agresor como un enfermo, ocultando la visión de la violencia hacia las mujeres como un fenómeno cultural.

En este sentido, la violencia contra las mujeres se asienta en una concepción cultural que otorga mayor valoración social a lo masculino en relación con lo femenino, y a partir de la cual una persona ejerce poder sobre otra. Una de las expresiones máximas de la violencia contra las mujeres es el feminicidio, como ya se ha planteado líneas atrás, que refiere al asesinato de mujeres por razones 
asociadas a su género. Para Marcela Lagarde (2014), comprende el conjunto de delitos de lesa humanidad que reúne crímenes, secuestros, desapariciones de mujeres y niñas ante el colapso institucional. Lo define como:

(...) el genocidio contra mujeres y sucede cuando las condiciones históricas generan prácticas sociales que permiten atentados contra la integridad, la salud, las libertades y la vida de las mujeres (...) todos tienen en común que las mujeres son usables, prescindibles, maltratables y desechables. Y, desde luego, todos coinciden en su infinita crueldad y son, de hecho, crímenes de odio contra las mujeres (Lagarde, 2004, p.2).

Según el Modelo de Protocolo Latinoamericano para la investigación de muertes violentas de mujeres por razones de género, se entiende el femicidio como,

(...) la muerte violenta de mujeres por razones de género ya sea que tenga lugar dentro de la familia, unidad doméstica o en cualquier otra relación interpersonal, en la comunidad, por parte de cualquier persona, o que sea perpetrada o tolerada por el Estado y sus agentes, por acción u omisión (OACNUDH y ONU MUJERES, 2014).

Adicionalmente, se ha diferenciado el femicidio, femicidio íntimo, femicidio no íntimo y por conexión: el primero refiere a los asesinatos cometidos por hombres con quién la víctima tenía o tuvo una relación íntima, familiar, de convivencia o afines a éstas; los femicidios no íntimos son aquellos asesinatos cometidos por hombres que no tenían dichas relaciones y que frecuentemente involucran un ataque sexual previo; y, los femicidios por conexión, hacen referencia a mujeres asesinadas en "la línea de fuego", de un hombre tratando de matar a una mujer, es el caso de mujeres familiares, niñas u otras mujeres que trataron de intervenir o simplemente fueron atrapadas en la acción femicida (Valenzuela, 2012).

La Organización Mundial de la Salud estima que, a nivel mundial, una de cada tres mujeres han sido víctimas de abuso sexual y o físico en su vida. Además, según el informe de homicidios por razón de género de la Oficina de las Naciones Unidas contra la Droga y el Delito, 6 de cada 10 mujeres víctimas de femicidios mueren a manos de sus parejas, ya sean actuales o de relaciones ya concluidas (UNODC, 2019).

El informe supra citado indica que, en el año 2017, la tasa de femicidios fue de 1.3 por 100.000 habitantes a nivel mundial, lo que representan 50.000 mujeres muertas por su condición de género. Como muestra la infografía $\mathbf{N}^{\circ} \mathbf{1}$, el continente africano es el que mantiene la tasa más alta de femicidios con un 3.1 por 100.000 habitantes, seguido por América con 1.6, Europa y Asia mantienen tasas relativamente bajas de 0.7 y 0.9 respectivamente. En el caso de Oceanía, si bien la cantidad de casos se podría catalogar como baja, 300 muertes de mujeres, por la densidad poblacional, su tasa si es considerable de un 1.3. 


\section{Infografía $\mathrm{N}^{\circ} 1$.}

\section{Número y tasa de femicidios a nivel global, por continente}

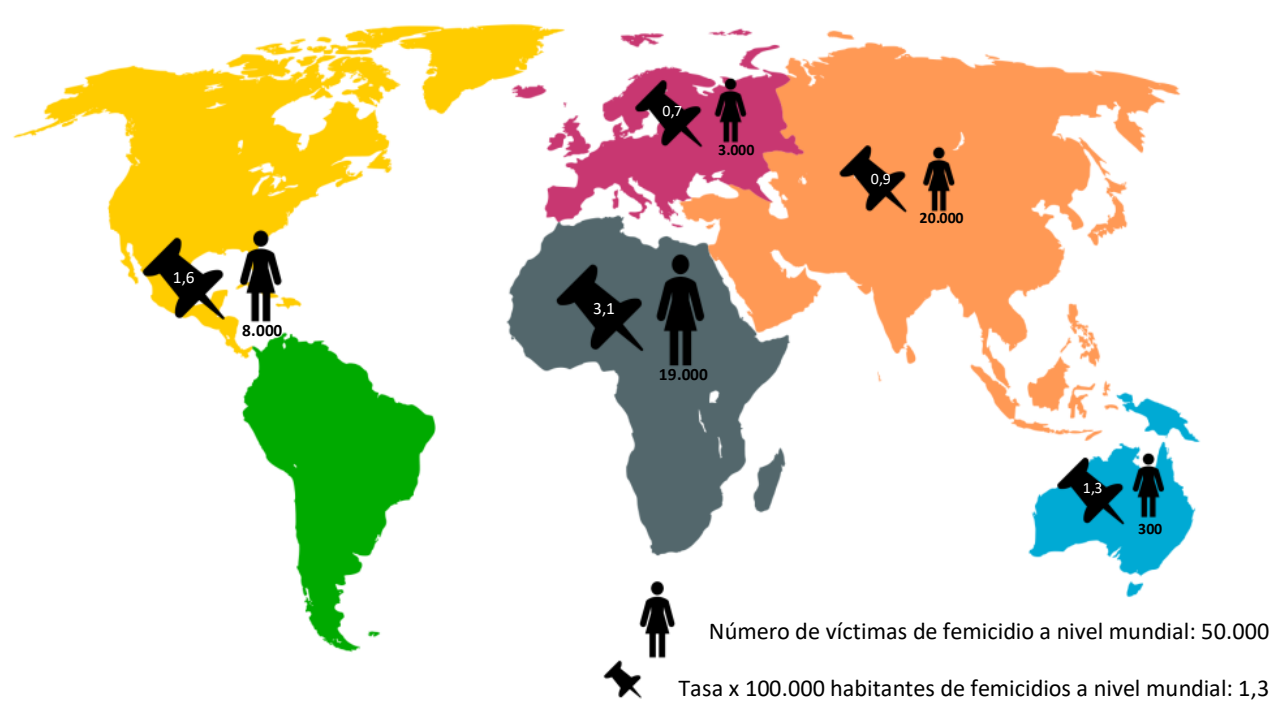

Fuente: Elaboración propia con base en UNODC, 2019.

Las causas más comunes de los homicidios de mujeres son la violencia doméstica, la violencia sexual y los llamados "conflictos de pareja", siendo la violencia por género la razón de más de la mitad de los homicidios de las mujeres (Sagot y Carcedo, 2000).

La violencia doméstica o intrafamiliar refiere a cualquier acto u omisión, directa o indirecta, llevada a cabo por algún integrante de la familia (por consanguinidad, afinidad o adopción hasta tercer grado inclusive) y cualquier condición que resulte de estos hechos que priven a otro integrante de iguales derechos o libertades, así como hechos que interfieran con su desarrollo y libertad de elegir. Incluye el abuso de carácter psicológico, sexual, físico o patrimonial (Piedra y Esquivel, 2012).

Este tipo de violencia es cometido con mayor frecuencia en contra de poblaciones vulnerables como niñas y niños, adolescentes, mujeres, personas adultas mayores o con alguna discapacidad y en menor proporción contra hombres adultos. Según el Instituto Nacional de las Mujeres (2020) los conceptos de violencia doméstica e intrafamiliar no tienen el mismo significado, aunque estos se utilicen como sinónimos en muchos de los casos, su diferencia reside en que la violencia doméstica ocurre contra familiares que viven en el mismo hogar y la violencia intrafamiliar contra familiares que no conviven en un mismo espacio físico. 
Castro (2012) indica que "la violencia doméstica no es exactamente lo mismo que la violencia intrafamiliar. La primera se refiere a la violencia que se ejerce y/o se sufre al interior del espacio doméstico, aún cuando los actores involucrados no tengan relaciones de parentesco entre sí; la segunda se refiere a la violencia que se ejerce y/o se sufre entre personas relacionadas por un vínculo de parentesco, independientemente del espacio físico donde la violencia tenga lugar (el hogar, la oficina, la calle, etc.). Suele haber un alto grado de coincidencia o intersección entre ambos conceptos, pero no son exactamente lo mismo" (p20-21).

Pero para su compresión, ambos conceptos comparten, en primer lugar, su carácter cíclico (se han identificado tres fases: a. la acumulación de tensión, b. el episodio agudo cuando se da el evento de violencia y c. la denominada "luna de miel" en la que se produce el arrepentimiento y el ciclo se vuelve a iniciar). $\mathrm{Y}$, en segundo lugar, su intensidad creciente, esa escalada de violencia que puede concluir en el femicidio o suicidio.

En Costa Rica, la cantidad de casos entrados a los Juzgados de violencia domésticas ascienden a más de 40 mil por año (periodo de 2010 al 2018), en el 2018 se registra la cifra más alta con 49.079 casos (Ver gráfico $\mathbf{N}^{\circ} \mathbf{1}$ ).

\section{Gráfico $\mathbf{N}^{\circ} 1$.}

Movimiento de trabajo registrado en los juzgados de Violencia Doméstica para el periodo 2010-2018

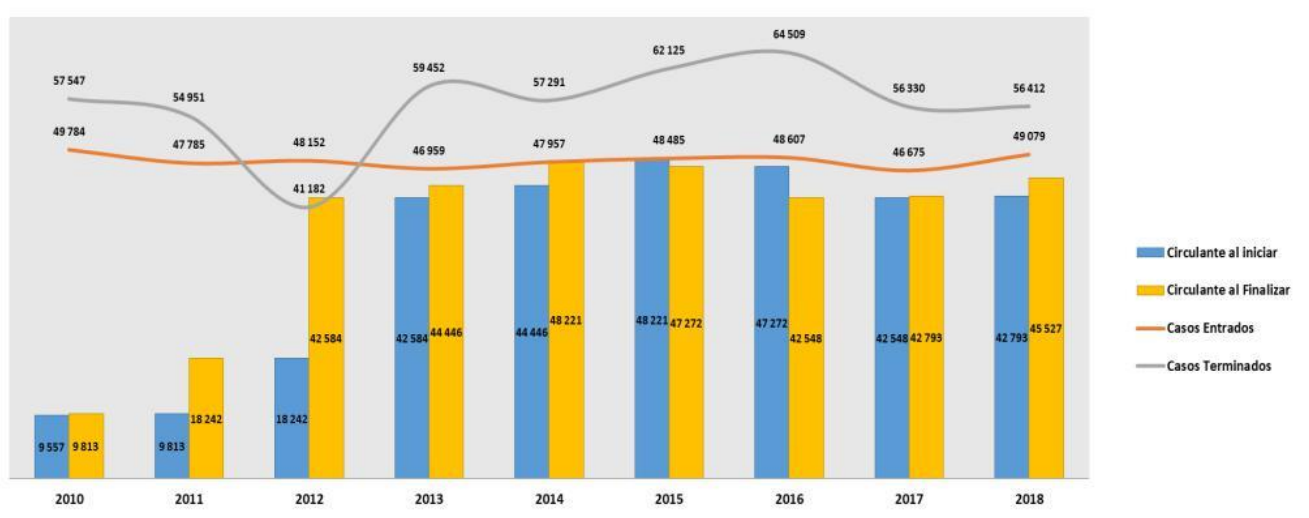

Fuente: Observatorio de Violencia de Género contra las Mujeres y el Acceso a la Justicia (2020)

Lo alarmante de la situación, también se puede observar al analizar la cantidad de mujeres, niñas y niños en situación de riesgo de muerte atendidas por los Centros Especializados de Atención y de Albergue Temporal para Mujeres Afectadas por Violencia (CEAAM) del INAMU, que son un recurso de 
emergencia para mujeres cuya vida e integridad física se encuentra amenazada y no cuentan con otro tipo de espacio seguro. Se han atendido en total en el periodo 2011 a 2018 a 7409 personas, de las cuales el $39.06 \%$ corresponde a mujeres, el $36,17 \%$ a niñas y de niños un $24,77 \%$; esto quiere decir que solo en situaciones de peligro de muerte se están atendiendo en promedio más de 700 personas al año (Ver gráfico $\mathbf{N}^{\circ} \mathbf{2}$ ).

\section{Gráfico $\mathbf{N}^{0} 2$.}

Cantidad de personas atendidas en CEAAM en situación de riesgo de muerte para el periodo de 2011 a 2018

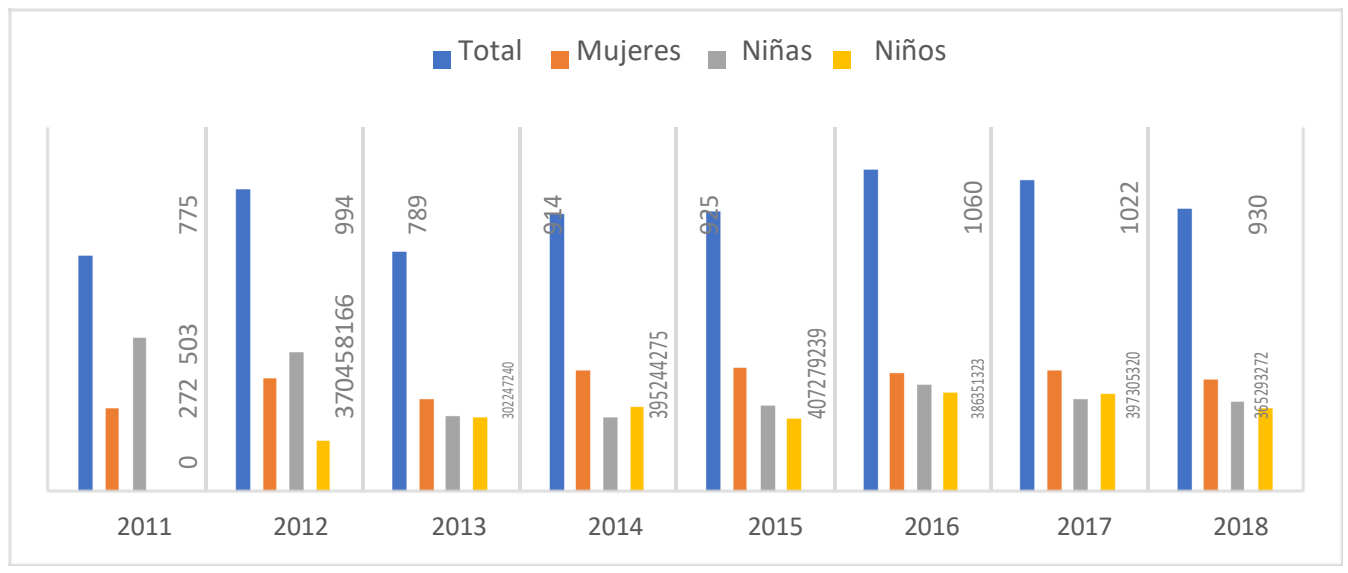

Fuente: Elaboración propia con datos de la Unidad de Investigación, INAMU.

Por otra parte, las cifras demuestran claramente que son las mujeres las principales víctimas de la violencia doméstica y que no es un problema compartido por igual por ambos sexos. Según datos del Observatorio de Violencia de Género contra las Mujeres y Acceso a la Justicia del Poder Judicial, solo en el año 2018 el 80\% de las víctimas atendidas por violencia doméstica son mujeres y el porcentaje de hombres es de alrededor del 20\%, que si se analiza por rango de edad (18 a 45 años) y relación víctima-victimario, queda claramente evidenciado que los hombres adultos en muy baja proporción son atendidos por este tipo de delito. Cabe señalar que la mayor cantidad de victimarios en este tipo de infracción siguen siendo los hombres (Ver gráfico $\mathbf{N}^{\circ} \mathbf{3}$ ). 
Gráfico $\mathbf{N}^{\circ} 3$.

Distribución presuntas víctimas y presuntos agresores /as por violencia doméstica por sexo durante el 2018

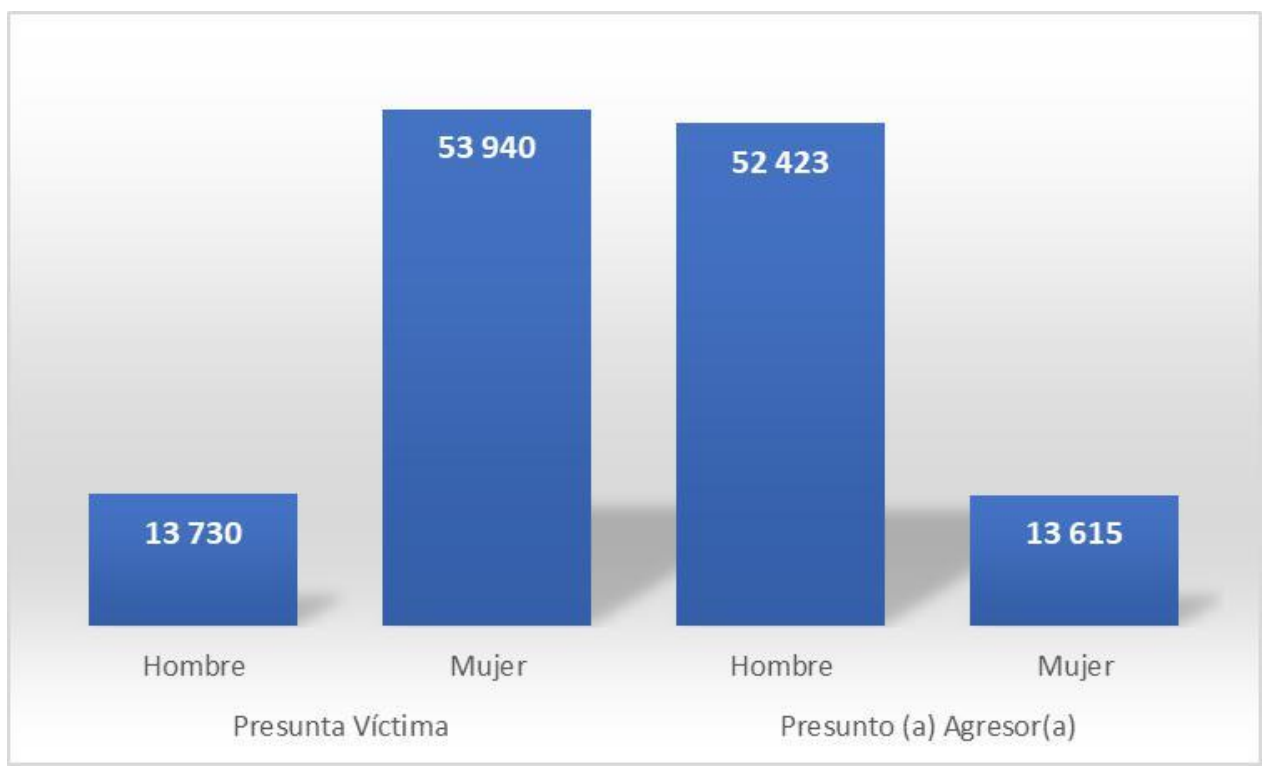

Fuente: Elaboración propia con datos del Observatorio de Violencia de Género contra las Mujeres y el Acceso a la Justicia (2020).

Adicionalmente, son las mujeres jóvenes en edad reproductiva y las niñas las principales víctimas atendidas (Ver gráfico $\mathbf{N}^{\circ} \mathbf{4}$ ), lo que coincide con lo planteado por ONU Mujeres (2015) que identifican como causas y factores de riesgo de discapacidad y muerte para mujeres entre las edades de 15 y 44 años la violación y violencia doméstica.

\section{Gráfico No 4.}

Distribución por rango de edad de los casos en los que la víctima es una mujer durante el 2018

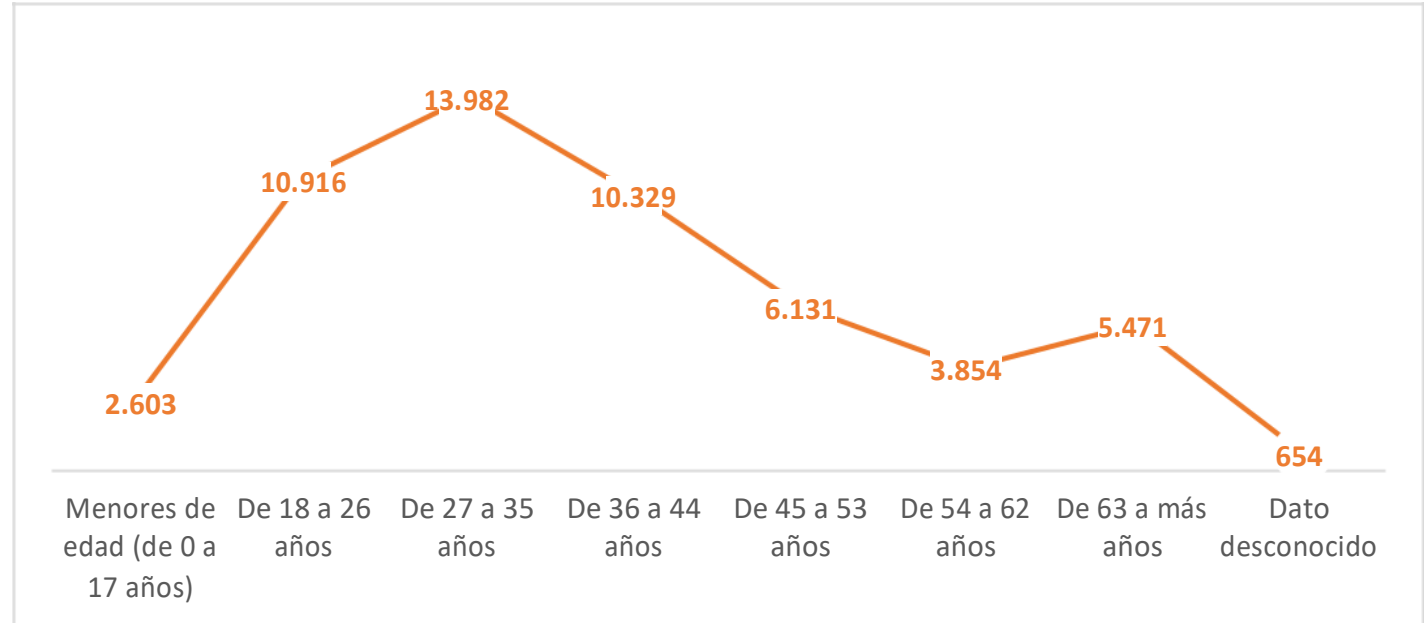

Fuente: Elaboración propia con datos del Observatorio de Violencia de Género contra las Mujeres y el Acceso a la Justicia (2020). 
La forma en que el Estado de Costa Rica reconoce la vulnerabilidad de las mujeres de ser víctimas de femicidio es por medio de la creación de la Ley de Penalización de la Violencia contra las Mujeres ${ }^{4}$, en la cual se tipificó el femicidio, en el artículo 21, como la muerte de una mujer a manos de su cónyuge o pareja actual; esta definición fue posteriormente ampliada, tomando como base la conceptualización de violencia de género que hace la Convención Belém do Pará, para incluir las muertes violentas de mujeres por razón de género, en donde no existe una relación de matrimonio o unión libre (novio, ex novio, ex esposo, ex compañero de unión de hecho, los que ocurren en ámbito público, hermano, hijo, padre, por ataque sexual, entre otros) y se contabilizan en las estadísticas judiciales como femicidios ampliados. ${ }^{5}$

Es importante señalar que esta ley no solo tipifica como delito el femicidio, sino otras formas de control y violencia contra las mujeres que el sistema patriarcal ha reproducido, como son el maltrato, amenazas, ofensas a la dignidad, incumplimiento de medida de protección y daño patrimonial. Delitos, que como se puede observar en el gráfico $\mathbf{N}^{\circ} \mathbf{5}$, son denunciados por las mujeres de manera considerable.

\footnotetext{
${ }^{4}$ La Ley de Penalización de Violencia contra las Mujeres ( $N^{\circ}$ 8589) se aprueba en la Asamblea Legislativa el 12 de abril de 2007 y se envía a la Presidencia de la República el 25 de abril de ese mismo año.

5 Es importante destacar, que si bien el uso del concepto permite visibilizar la muerte de mujeres por su condición de género, esto tiene una intencionalidad política, ya que estos casos son procesados bajo otras tipología penales, como homicidio calificado u homicidio simple.
} 


\section{Gráfico $\mathbf{N}^{\circ} 5$.}

Cantidad de casos netos entrados en las Fiscalías Penales de Adultos por concepto de delitos de la Ley de Penalización de Violencia contra la Mujer (LPVCM).

Periodo 2014-2018

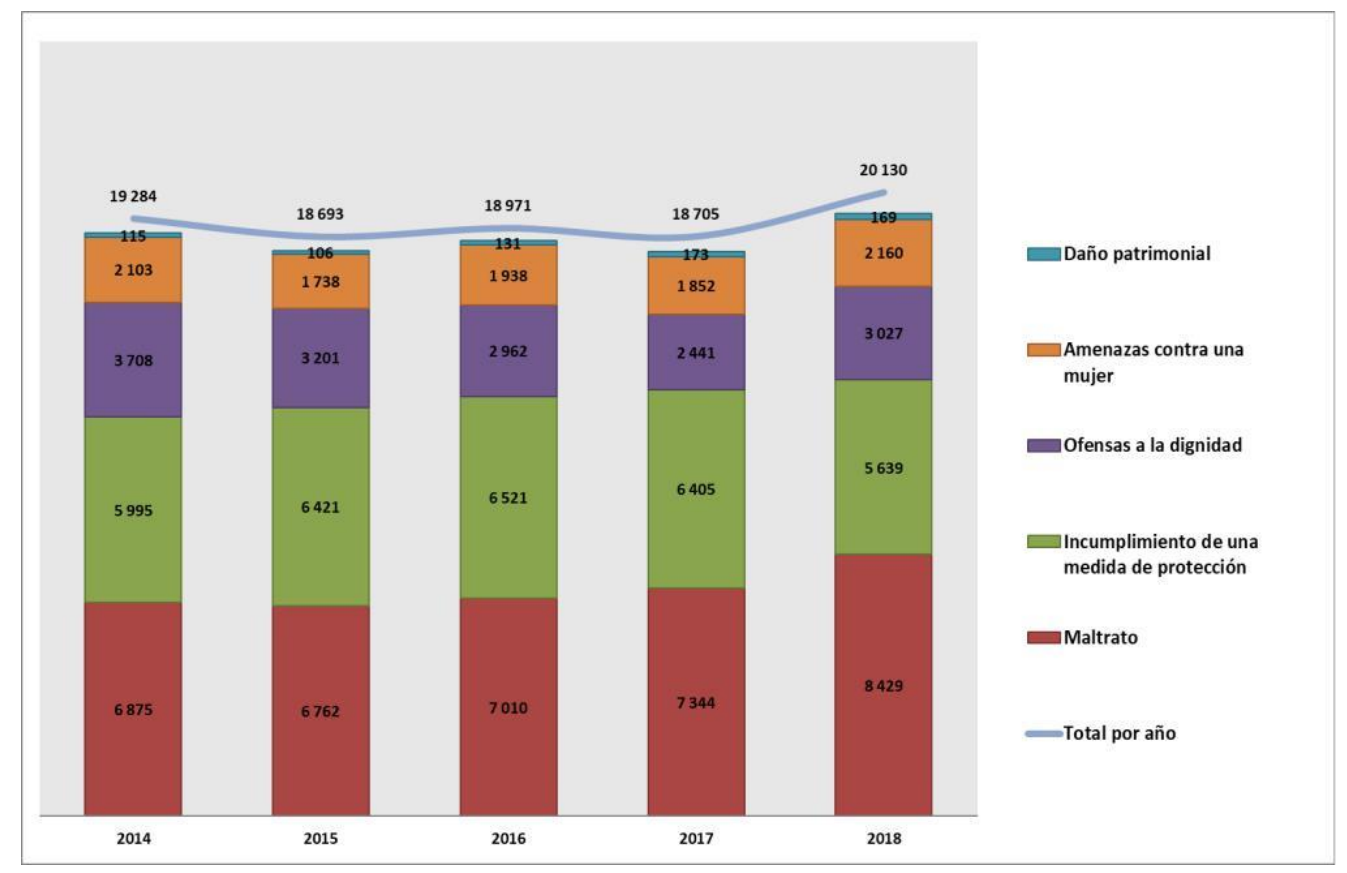

Fuente: Observatorio de Violencia de Género contra las Mujeres y el Acceso a la Justicia (2020).

Es importante destacar, que las actuaciones policiales según el motivo de violencia contra las mujeres se concentran en agresión psicológica, tipificada en la Ley de Violencia Doméstica, con la mayor cantidad de eventos, con valores de $30,0 \%$ (2016), 34\% (2017) y 40\% (2015), lo que contempla las ofensas a la dignidad, restricción a la autodeterminación y amenazas contra las mujeres. Las intervenciones por la violencia física, por la Ley de Penalización de Violencia contra la Mujer (LPCVM) corresponden a un 27\% (2016, 2017) y 17\% (2015) respectivamente, incluye el maltrato y el femicidio (Ver gráfico $\mathbf{N}^{\circ} \mathbf{6}$ ). 


\section{Gráfico $\mathbf{N}^{\circ}$ 6.}

\section{Porcentaje de actuaciones policiales por Violencia Doméstica según motivo para el periodo 2015-2017}

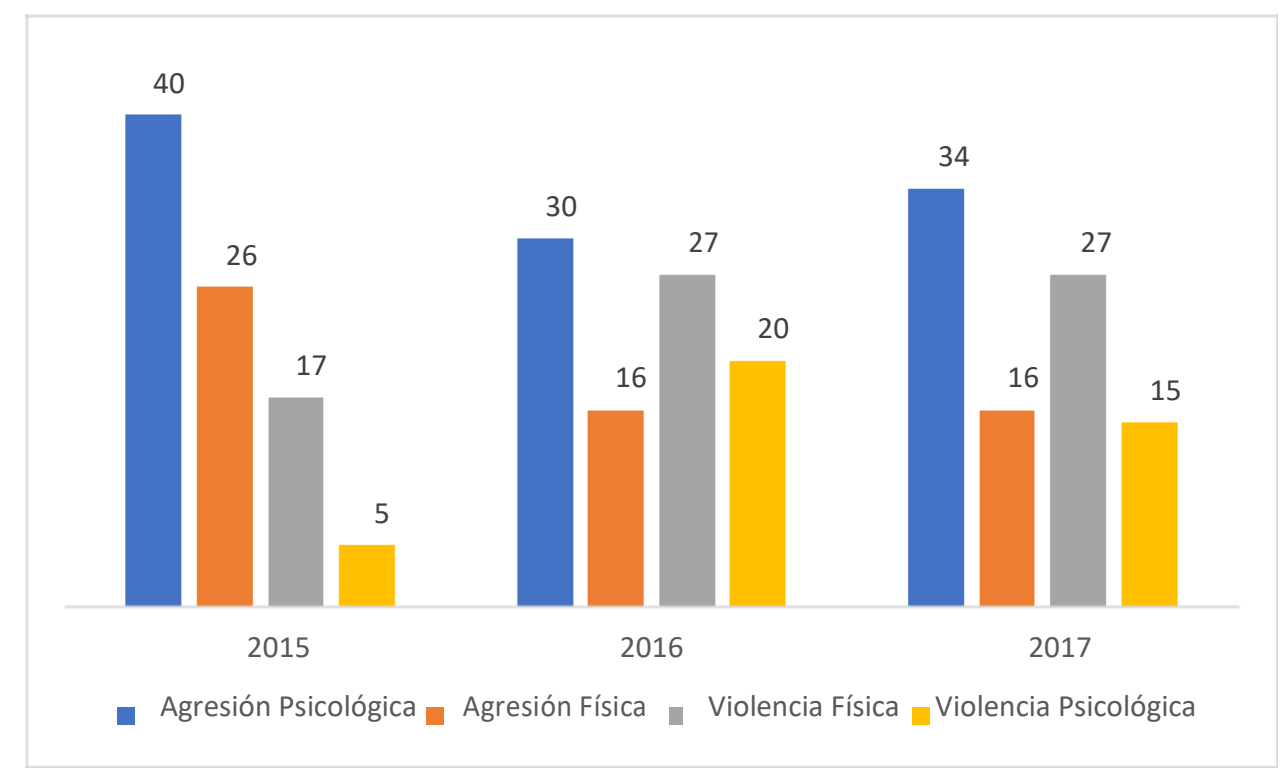

Fuente: COMESCO, 2018, p 33.

Según datos suministrados por la Comisión Técnica Interinstitucional sobre Estadísticas de Convivencia y Seguridad Ciudadana (2018), la Fuerza Pública aprehende cada año alrededor de 10.000 personas (en promedio una cada hora) en casos de violencia doméstica o intrafamiliar. La mayoría de las actuaciones policiales por casos de violencia fueron para la atención de mujeres víctimas (Ver gráfico $\mathbf{N}^{\circ} \mathbf{7}$ ). Por otra parte, generalmente el juzgado, cuando la persona agresora es detenida por primera vez, como medida de protección para la víctima, dicta medidas cautelares y se le prohíbe que la perturbe o intimide a algún integrante de la familia, se le impide el acceso al domicilio, trabajo o lugar de estudio de la víctima, debe salir del domicilio y la víctima puede solicitar auxilio policial, en caso de que la persona agresora incumpla estas medidas. Una vez dictadas las medidas, que incluyen el desalojo de la persona agresora, la Fuerza Pública le acompaña a la casa para cumplir lo que el juzgado ordena (se le retira la llave de la vivienda, se le indica que debe sacar sus cosas personales, así como herramientas de trabajo y se le acompaña donde familiares o personas conocidas a quienes se les indica que ha sido retirado de su núcleo familiar por hechos de violencia doméstica) (COMESCO, 2018). 
Gráfico $\mathbf{N}^{\circ} 7$.

Porcentaje de actuaciones policiales por casos de Violencia Doméstica o violaciones de medidas de protección de la Fuerza según tipo de ley y sexo de las personas ofendidas para el periodo 2016-2017

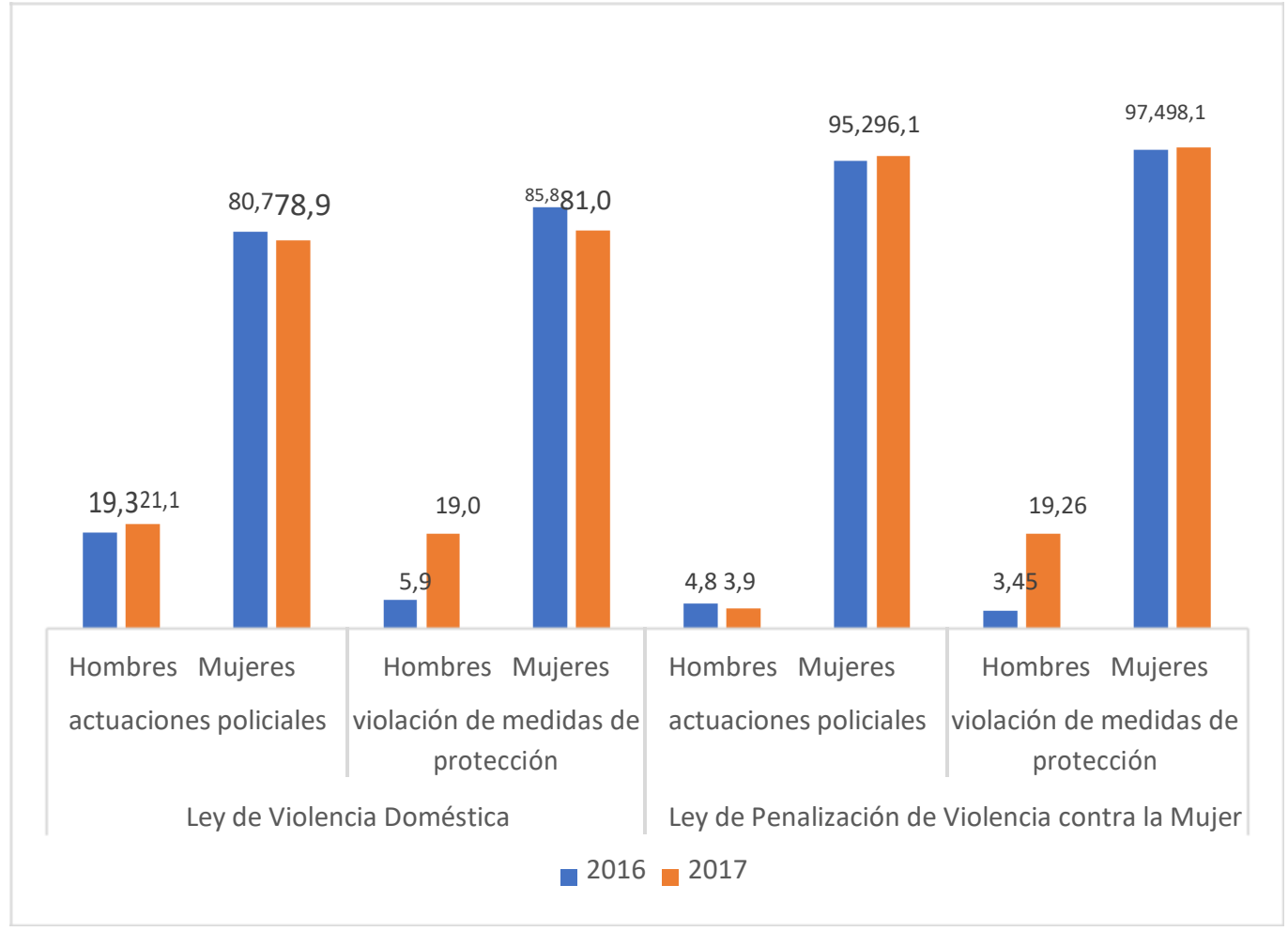

Fuente: Elaboración propia con base en COMESCO, 2018, p 32-39.

No obstante, como se puede observar en el gráfico $\mathbf{N}^{\circ} \mathbf{7}$, las intervenciones policiales por violación a las medidas de protección son altas e insuficientes para garantizar la protección de las mujeres. La violación de estas se da en más de un $80 \%$ en los casos de la Ley de Violencia Doméstica y en la Ley de Penalización de la Violencia es aún peor, ya que sobre pasa el 97\%, lo que está estrechamente ligado con los femicidios cometidos. Cabe señalar que la Fuerza Pública no interviene de oficio, sino que es ante solicitud de la persona ofendida, es decir, la que cuenta con la medida de protección, lo que deja claro que no sólo son las mujeres las que en mayor proporción las solicitan, sino que también son las que deben acudir a la policía para que las mismas se cumplan.

Con respecto a los femicidios, el pico de muertes de mujeres se da en 2011 cuando se registraron 42 casos. En relación con este tipo de delito el Poder Judicial registra una cantidad de 13 casos al 17 de diciembre del 2019, lo que significa, en promedio, un femicidio al mes (Ver gráfico $\mathbf{N}^{\circ} \mathbf{8}$ ). 
Gráfico No8.

Cantidad de femicidios registrados durante el periodo 2007-2019

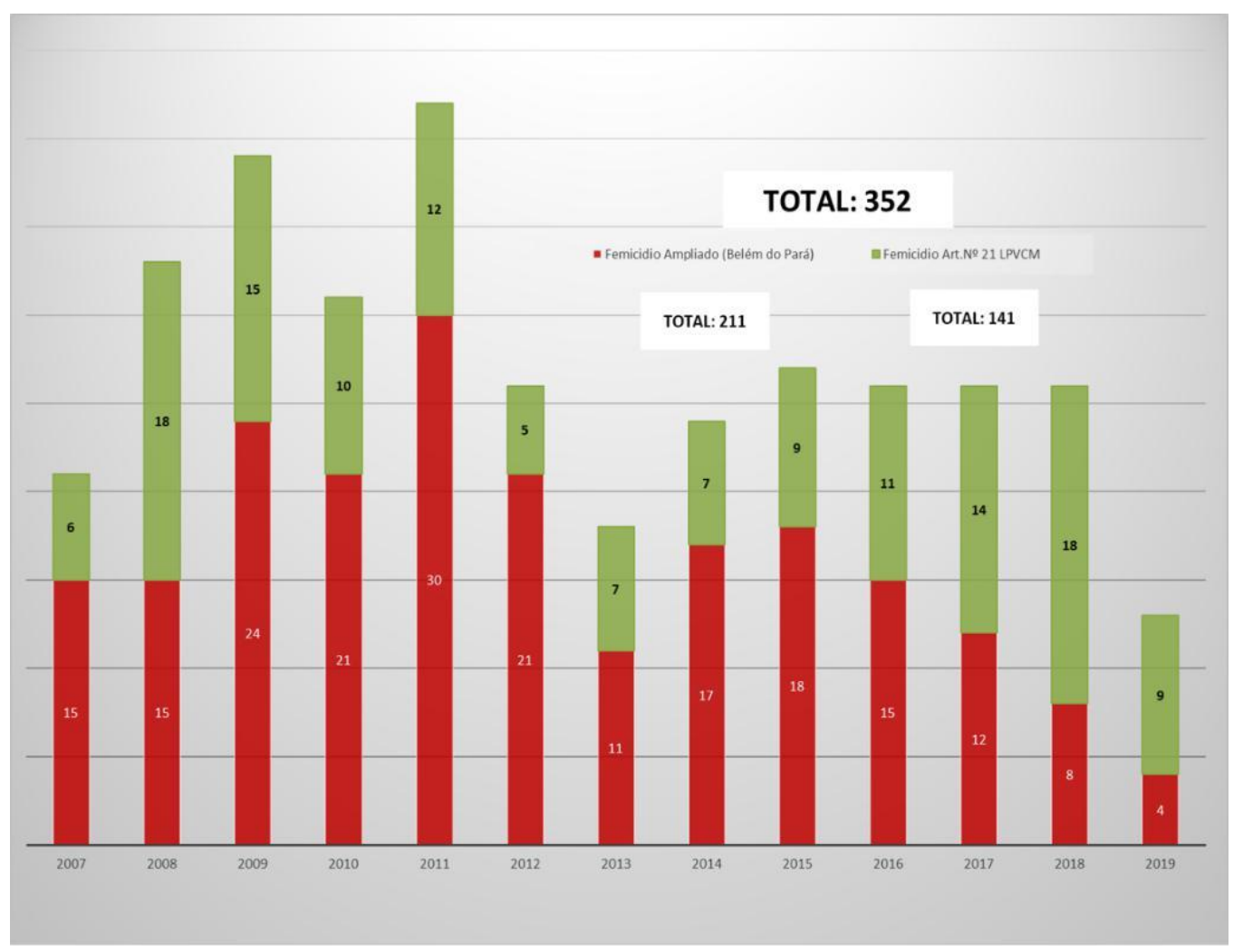

Fuente: Observatorio de Violencia de Género contra las Mujeres y el Acceso a la Justicia (2020).

Por otra parte, el uso de arma de fuego y arma blanca, son los principales métodos empleados para cometer los femicidios (Ver tabla $\mathbf{N}^{\circ} \mathbf{1}$ ). Según datos del Ministerio de Seguridad Pública, de incidentes reportados a la central de comunicaciones en el 2018, se atendieron 50 mujeres heridas por arma de fuego y 30 por arma blanca, este comportamiento podría indicar que el mayor acceso a armas de fuego se refleja en un mayor uso para ejercer violencia en contra de las mujeres, ya que son heridas o amenazadas y la sola presencia de un arma en un contexto de violencia doméstica o intrafamiliar genera mayores niveles de violencia psicológica y estrés en las mujeres, aunque no se materialice en femicidios.

Lo anterior concuerda con varios estudios realizados desde el año 2005 en América Latina por el Grupo de Estudios de Paz, en Río de Janeiro (Brasil), San Salvador (El Salvador) y en el continente africano, especialmente en Maputo (Mozambique), que han logrado identificar cómo la demanda de armas pequeñas está conformada por las identidades y relaciones de género, y cómo expectativas y roles de género son un producto de y son afectados por la violencia armada. Además, se ha identificado que la presencia de un arma de fuego en el hogar 
también puede facilitar la violencia contra las mujeres y las niñas, se utilizan con frecuencia para amenazar a la pareja en casos de violencia doméstica aumentando las posibilidades de que los resultados de la violencia doméstica lleven a femicidios (Initiative for Peacebuilding, 2011).

Tabla $\mathbf{N}^{\circ} 1$.

Principales métodos empleados para cometer femicidios y cantidad de casos en Costa Rica para el periodo 2008-2019

\begin{tabular}{|c|c|c|c|c|}
\hline \multirow{2}{*}{ Año } & \multicolumn{5}{|c|}{ Método empleado } \\
\cline { 2 - 5 } & Arma de Fuego & Arma Blanca & Asfixia & Otro \\
\hline $\mathbf{2 0 0 8}$ & 5 & 8 & 4 & 1 \\
\hline $\mathbf{2 0 0 9}$ & 1 & 8 & 4 & 2 \\
\hline $\mathbf{2 0 1 0}$ & 4 & 0 & 4 & 2 \\
\hline $\mathbf{2 0 1 1}$ & 8 & 3 & 1 & 0 \\
\hline $\mathbf{2 0 1 2}$ & 2 & 1 & 0 & 2 \\
\hline $\mathbf{2 0 1 3}$ & 4 & 1 & 2 & 1 \\
\hline $\mathbf{2 0 1 4}$ & 2 & 3 & 0 & 1 \\
\hline $\mathbf{2 0 1 5}$ & 5 & 2 & 1 & 1 \\
\hline $\mathbf{2 0 1 6}$ & 3 & 5 & 2 & 0 \\
\hline $\mathbf{2 0 1 7}$ & 8 & 5 & 1 & 6 \\
\hline $\mathbf{2 0 1 8}$ & 7 & 11 & 2 & 3 \\
\hline $\mathbf{2 0 1 9}$ & 4 & 6 & 0 & 19 \\
\hline Total & 53 & 53 & 21 & 0 \\
\hline
\end{tabular}

Fuente: Elaboración propia a partir de las estadísticas del Departamento de Planificación. Sección de Estadística del Poder Judicial de Costa Rica.

Si se hace un balance general de todos los delitos que trata la ley de Penalización de la Violencia, las demandas son muchas, pero las condenas de prisión muy pocas, lo cual se refleja en la población carcelaria que cumple penas por infracciones a esta ley. La relación entre el alto número de denuncias por los delitos cometidos y el bajo número de personas que se encuentran en algún centro penitenciario por autoría de algún delito contemplado en la Ley $N^{\circ} 8589$ podría explicarse, en lo formal, en que las sentencias establecen sanciones de privación de libertad, penas alternativas, prestación de servicios de utilidad pública, entre 
otros castigos de acuerdo con la gravedad de la denuncia o una sentencia absolutoria.

Ahora bien, si retomamos la incapacidad de las sociedades de cuestionarse las bases de la legitimidad del poder que les oprime, se puede plantear que el alto número de rechazos se debe a que las mujeres víctimas de violencia terminan por retirar los cargos por múltiples razones (pasa mucho tiempo entre la presentación de la denuncia y las indagaciones, miedo al agresor, dependencia económica) y el Ministerio Público, en lugar de cuestionar las razones estructurales del retiro de las denuncias y de manera proactiva continuar con los casos, dan por cerrados los procesos sin importar que existan otras pruebas para lograr una condena (partes policiales de agresión, registros médicos de la víctima, prueba testimonial de terceras personas, entre otros). En este sentido, el concepto violencia simbólica se vuelve vital para entender que, en un sistema de justicia todavía patriarcal, las denuncias de violencia contra las mujeres sean consideradas temas de segunda categoría en relación con otros casos penales. ${ }^{6}$

La situación de violencia contra las mujeres no cambia favorablemente cuando los datos son agrupados de acuerdo con la provincia donde se denuncia la infracción por violencia doméstica. Históricamente, la provincia de San José sigue ocupando los primeros puestos junto con Alajuela, Puntarenas y Guanacaste, pero si el análisis se realiza por medio de una tasa por cada 1.000 habitantes, los datos varían, con Puntarenas en primer lugar con una tasa de 15.76, Guanacaste con 14.30 y Alajuela con 9.22, dejando a San José y Cartago como las provincias con menor incidencia, lo cual coincide, en el caso de Puntarenas y Alajuela, con provincias con mayor cantidad de casos femicidios (Ver mapa $\mathbf{N}^{\circ} \mathbf{1}$ ).

${ }^{6}$ Como bien lo plantea Monserrat Sagot (1995) todo sistema de dominación se compone de dos elementos, su estructura y su ideología. El componente de la estructura se manifiesta en la organización jerárquica de las instituciones y de las relaciones sociales, en este caso el Poder Judicial representado en el Ministerio Público y la ideología es el medio de apoyo del principio del orden jerárquico, es la racionalización de la desigualdad que no coloca a la violencia contra las mujeres en el centro del quehacer judicial. 
Figura 1.

Mapa de denuncias por número de casos y tasa por 1.000 habitantes por Violencia Doméstica por Provincia en Costa Rica para el periodo 2018
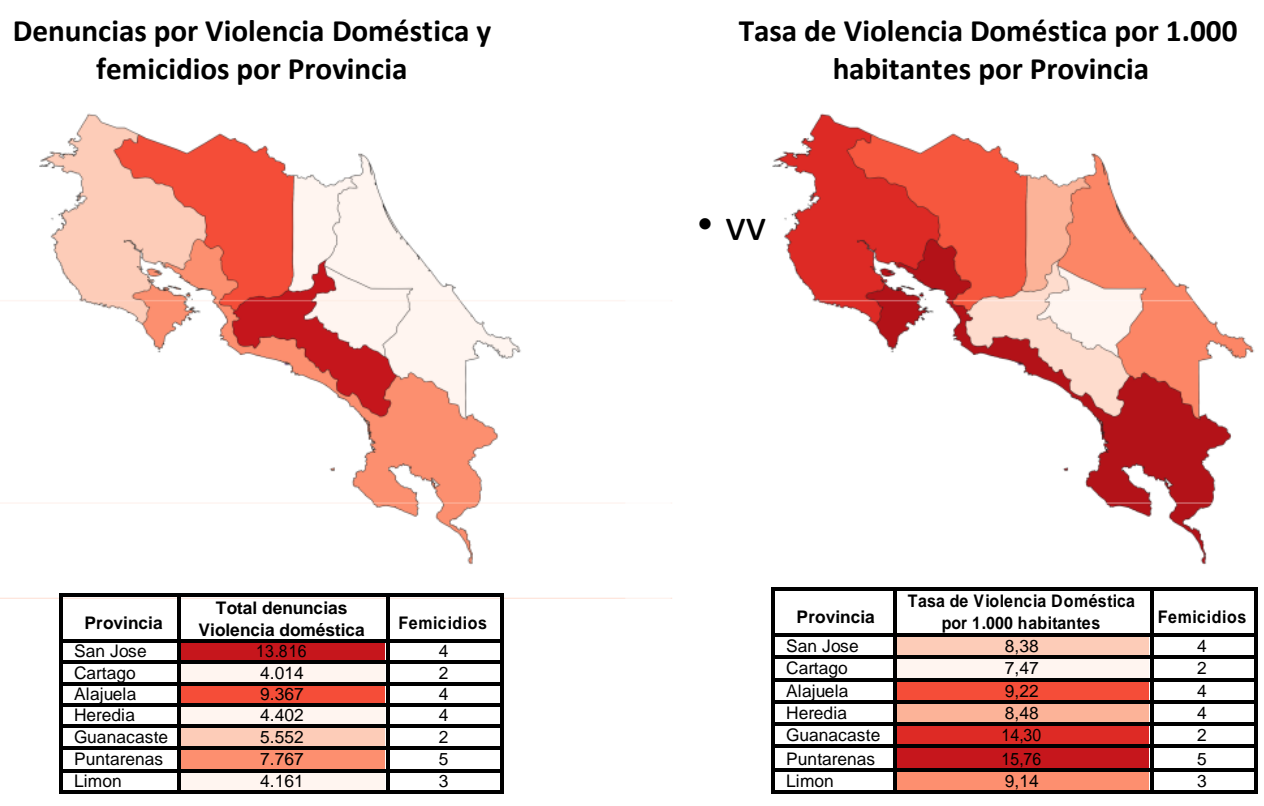

Fuente: Elaboración propia con datos del Observatorio de Violencia de Género contra las Mujeres y el Acceso a la Justicia (2020).

Si vemos estos datos a la luz de la Encuesta Nacional de Hogares (Enaho) del año 2019, que realiza el Instituto Nacional de Estadística y Censos, se encuentran las regiones Brunca y Pacífico Central, con un 30,3\% y 29,8\% de hogares en pobreza y un $9,2 \%$ y $9,1 \%$ en pobreza extrema respectivamente, lo que concuerda con la provincia con la mayor tasa de denuncias por violencia doméstica y más femicidios, que es Puntarenas y, adicionalmente, con poca presencia o cercanía de instituciones de prevención, atención y sanción de la violencia contra las mujeres. Esta relación indica la necesidad de trabajar con las mujeres de estas regiones en su autonomía económica, para que puedan contar no solo con las herramientas de protección que el sistema judicial les brinda y procesos de empoderamiento, sino también con los medios económicos para no depender de su agresor.

Adicionalmente, es vital que la institucionalidad pública y las familias de estas mujeres entiendan, que una víctima de violencia llega a tener un profundo sentimiento de indefensión que debilita su capacidad de solucionar problemas y la motivación para afrontarlos, favoreciendo de esta forma la permanencia de la mujer en la relación violenta (Seligman, 1975), no es que les gusta vivir de esa forma, como muchas veces se afirma. Lenore Walker (1989) plantea que una mayor permanencia en una relación violenta puede estar relacionada con haber vivido más experiencias de indefensión en la infancia, por esto la importancia de 
trabajar el tema de prevención de la violencia y de igualdad entre los géneros desde edades tempranas y en todas las regiones del país.

\section{APUNTES FINALES}

Las estadísticas mundiales indican que el problema de la violencia contra las mujeres alcanza proporciones pandémicas, es generalizada, sistémica y tiene un fuerte arraigo cultural, por lo que es necesario actuar rápido y desde sus cimientos, para eliminar esa desigualdad que consagra el patriarcado y normaliza la inferioridad de un género respecto al otro, lo que ha permitido legitimar el maltrato que sufren las mujeres.

Deconstruir las estructuras patriarcales, que tienen como principal consecuencia la naturalización de la violencia hacia las mujeres es un largo camino por recorrer, ya que la violencia sexista es una cuestión política, social, cultural, económica y de Derechos Humanos. Un primer paso, es hacer visible la violencia contra las mujeres en todas sus formas y desde una visión integral, ya que trasciende las estadísticas policiales o judiciales sobre violencia y delito.

También, es necesario trascender la concepción asistencialista que crea instituciones y servicios públicos para atender la situación post violencia, es decir, cuando las mujeres se han convertido en víctimas y más bien fortalecer las estrategias y recursos para la prevención y promoción del derecho de las mujeres a vivir libres de violencia. Se trata de considerar a las mujeres como ciudadanas plenas para decidir respecto de sus vidas y garantizar desde el Estado condiciones que remuevan la desigualdad en todas sus formas.

Debemos encauzar las acciones hacia la búsqueda del ejercicio pleno de la ciudadanía, de hombres y mujeres en igualdad de condiciones, y en particular, visibilizar las necesidades específicas de las mujeres. Lo que significa garantizarles a las mujeres que sus derechos no van a ser vulnerados y que van a hacer ejercicio de estos sin limitaciones, sin prejuicios, sin coacción; refiere a la construcción de una sociedad donde la justicia sea pronta y cumplida y en la que no se vea a las mujeres como víctimas-vulnerables solamente por su condición de género. En este sentido, como ya he planteado en otros estudios sobre seguridad ciudadana con enfoque de género y prevención de la violencia contra las mujeres, se deben incluir como mínimo acciones tendientes a:

$\checkmark$ El cambio cultural: orientado hacia la lucha contra la cultura patriarcal, el uso de la violencia como forma de dominación, que contemple una socialización de género que se aleje de las construcciones tradicionales de masculinidad y feminidad, para lo cual el sistema educativo en su conjunto, como herramienta de cambio, es primordial. 
$\checkmark$ Institucionalizar: la perspectiva de género y la prevención de la violencia contra las mujeres deben ser parte de las políticas de seguridad ciudadana y de criminalidad de forma transversal y ser incorporada de manera visible en los presupuestos de todas las instituciones encargadas de prestar servicios y hacer cumplir esta política.

$\checkmark$ Los instrumentos legales existentes en el país son recursos a utilizar: el marco legal de protección de los derechos humanos de las mujeres debe ser promocionados de manera más efectiva, son necesarias las campañas de información para que más y más mujeres exijan los derechos que les corresponden. Adicionalmente, se debe crear un sistema de seguimiento y evaluación de la normativa existente, con el fin de determinar el por qué existen aún vacíos en la aplicación de las leyes y cómo subsanarlos.

$\checkmark$ Fortalecer el ejercicio de la ciudadanía de las mujeres: ser ciudadana es más que ser poseedora de derechos, significa hacerlos efectivos. El Estado es el responsable de garantizar la verdadera ciudadanía de las mujeres, ya que los derechos humanos del género femenino no deben quedar solamente en el papel, en detrimento de su pleno y libre ejercicio. No se puede hablar de ciudadanía mientras se es agredida, se sufre violencia de cualquier tipo, se es discriminada, se gana menos por igual trabajo, no se tiene tranquilidad en las calles o en la casa, se tiene la responsabilidad total del cuidado de niños, niñas, personas adultas mayores o con alguna discapacidad, entre otros. Además, en el caso de las mujeres, que han sido históricamente excluidas de la toma de decisiones sobre estos aspectos, se hace todavía más importante generar los mecanismos para su participación directa y activa en la elaboración de políticas públicas como parte del ejercicio de su propia ciudadanía.

$\checkmark$ Crear, potenciar y fortalecer alianzas estratégicas entre las instituciones nacionales, los gobiernos locales, empresa privada, organizaciones de la sociedad civil, organizaciones de mujeres, entre otros, para lograr una implementación eficiente de una política de prevención de la violencia con enfoque de género.

$\checkmark$ Generar conocimiento, información y medición confiable (cualitativa y cuantitativa) con el objeto de tener una representación diferenciada del contexto donde se desarrollan mujeres y hombres. Es necesario contar con datos exactos y comparables sobre la violencia a nivel local, nacional e internacional para fortalecer los esfuerzos de atención y prevención, al ayudar en la compresión de la magnitud del problema y de guía para el diseño de las intervenciones. Sin embargo, se debe reconocer que medir la prevalencia real de la violencia contra las mujeres en todas sus manifestaciones es una tarea compleja.

$\checkmark$ Educar y sensibilizar: la sensibilización y la educación sobre la especificidad de género que subyace en la violencia contra las mujeres debe ser una 
cuestión fundamental para toda la ciudadanía. Es necesario fomentar y generar procesos de diálogo, sensibilización y capacitación orientados a toda la población (hombres y mujeres) para desnaturalizar la desigualdad, la discriminación, la dominación y la violencia contra las mujeres.

$\checkmark$ El derecho de las mujeres a una vida libre de violencia es un asunto de oportunidades: el Estado debe garantizar tanto la autonomía física (se es dueña de su cuerpo) como la autonomía económica (empoderamiento económico) de las mujeres, como uno de los medios para que se rompan los vínculos de dependencia y control, elemento que en algunas ocasiones es justificante para resistir una situación de violencia en el hogar.

En síntesis, es primordial generar un cambio que transforme la sociedad patriarcal en una en la que exista una nueva relación entre hombres y mujeres, en la que se respete su derecho a no solo sentirse seguras sino también a garantizarles seguridad en todos los niveles (casa, colegio, escuela, trabajo, calle, entre otros), que se entienda y se viva la seguridad como un bien público, lo que va a tener un impacto positivo en la calidad de vida de las mujeres y los hombres.

\section{FUENTES CONSULTADAS'}

Aguilar, V. (2002). La violencia simbólica entretejida en la enseñanza del Derecho Penal (Tesis de maestría). Universidad de Costa Rica, San José, Costa Rica.

Amorós, C. (2005). Dimensiones de poder en la teoría feminista. Revista Internacional de Filosofía Política. 25, 11-34.

Bourdieu, P. (2000). La dominación masculina. Barcelona, España: Anagrama.

Briceño-León, R. (2002). Introducción. La nueva violencia urbana de América Latina. En: Briceño-León, R. (Comp.). Violencia, sociedad y justicia en América Latina (pp. 13-26). Buenos Aires, Argentina: Consejo Latinoamericano de Ciencias Sociales (CLACSO)

Caputti, J. y Russell, D. (1992). Femicide: sexist terrorism against women. En: Radford, J. y Russell, D. (Eds.). Femicide. The politics of woman killing (pp. 13-26). Nueva York, Estados Unidos: Twayne Publishers.

Carcedo, A. (2006). Cuadernos de Desarrollo Humano N². Seguridad ciudadana de las mujeres. San José, Costa Rica: Programa de Naciones Unidas para el

Desarrollo. Recuperado de: http://www.dhl.hegoa.edu.es/ficheros/0000/0279/Seguridad_ciudadana_m ujeres_y_desarrollo_humano.pdf.

Castro, R. (2012). Problemas conceptuales en el estudio de la violencia de género. Controversias y debates a tomar en cuenta. En: Baca Tavira, N. y 
Vélez Bautista, G. (Coords.). Violencia, género y la persistencia de la desigualdad en el Estado de México (pp. 17-38). Buenos Aires. Argentina: Editorial Mnemosyne.

CEFEMINA (2010). No olvidamos ni aceptamos: femicidio en Centroamérica 2000-2006. San José, Costa Rica: Asociación Centro Feminista de Información y Acción.

Chacón, M.; Lizano, M. y Murillo, E. (2012). Fundamentos políticos e ideológicos que legitiman la violencia feminicida por parte del Estado costarricense, a partir del INAMU y el Poder Judicial (Tesis de licenciatura). Universidad de Costa Rica, San José, Costa Rica.

Chiarotti, S. (2011). Contribuciones al debate sobre la tipificación penal del femicidio/feminicidio (S. Chiarotti, Ed.). Lima, Perú: Comité de América Latina y el Caribe para la Defensa de los Derechos de las Mujeres.

COMESCO (2018). Violencia contra las mujeres en Costa Rica período 2015 2017. San José, Costa Rica: Comisión Técnica Institucional sobre Estadísticas de Convivencia y Seguridad Ciudadana.

de las Herras, S. (2009). Aproximación a las teorías feministas. Universitas.

Revista de Filosofía, Derecho y Política. 9, 45-82.

Facio, A y Fries, L. (1999). Género y derecho. Santiago, Chile: LOM Ediciones.

Fernández, A.M. (2012). FEMICIDIOS: la ferocidad del patriarcado. Revista Nomadías. 16, 47-73.

Haimovich, P.L. (1990). El concepto de los malos tratos. Ideología y representaciones sociales. En: Sánchez, C. y Maqueira d'Angelo, V. (Coords.). Violencia y sociedad patriarcal (pp. 81-104). Madrid, España: Pablo Iglesias.

Hidalgo, A. (2009). Femicidio en Costa Rica 2000-2004. San José: Instituto Nacional de las Mujeres y Centro Feminista de Información y Acción.

INAMU (2013). La representación del femicidio en la prensa escrita durante el período 2005-2009. San José, Costa Rica: Instituto Nacional de las Mujeres.

Recuperado de: https://www.inamu.go.cr/documents/10179/20949/La+representaci\%C3\% $\mathrm{B} 3 \mathrm{n}+\mathrm{del}+$ femicidio+en+la+prensa+escrita+durante+el+periodo+2005+200 9+(2013)/c588f7dc-a77d-42ad-82b4-1b3cda7550e1.

Initiative for Peacebuilding (2011). Women and gun violence: key findings from Río de Janeiro (Brazil), San Salvador (El Salvador) and Maputo (Mozambique). Bruselas, Bélgica: Peace Studies Group (NEP/CES). 
Instituto Nacional de Estadística y Censos (2019). Encuesta Nacional de Hogares. San José, Costa Rica. Recuperado en https://www.inec.cr/encuestas/encuesta-nacional-de-hogares.

Instituto Nacional de las Mujeres (2020). Femicidio. San José, Costa Rica: Instituto Nacional de las Mujeres. Recuperado en https://www.inamu.go.cr/web/inamu/femicidio.

Lagarde, M. (2004). Por la vida y libertad de las mujeres: fin al feminicidio/Día V Juárez. Fem. 28(255), 26-34.

Lagarde, M. (2006). El derecho humano de las mujeres a una vida libre de violencia. En: Maqueira d'Angelo, V. (Coord.). Mujeres, globalización y derechos humanos (pp. 477-534). Madrid, España: Cátedra.

Lagarde, M. (2008). Antropología, feminicidio y política: violencia femicida y derechos humanos de las mujeres. En: Bullen, M.L. y Diez Mintegui, M.C. (Coords.). Retos teóricos y nuevas prácticas (pp. 209-240). San Sebastián, España: Ankulegi.

Lagarde, M. (2014). El feminismo de mi vida. Hitos, claves y topías. México D.F., México: Gobierno del Distrito Federal e Instituto de las Mujeres del Distrito Federal.

Ley N8589 Ley de Penalización de la Violencia contra las Mujeres. Diario Oficial La Gaceta, San José, Costa Rica, 30 de mayo de 2007

López Méndez, I. (2016). Género en las Políticas de Seguridad. La integración de la perspectiva de género en las instituciones policiales de América Latina y el Caribe. Madrid, España: Eurosocial.

OACNUDH y ONU MUJERES (2014). Modelo de protocolo latinoamericano de investigación de las muertes violentas de mujeres por razones de género (femicidio/feminicidio). Ciudad de Panamá, Panamá: Oficina Regional para América Central del Alto Comisionado de las Naciones Unidas para los Derechos Humanos (OACNUDH) y Oficina Regional para las Américas y el Caribe de la Entidad de las Naciones Unidas para la Igualdad de Género y el Empoderamiento de las Mujeres (ONU Mujeres).

Observatorio de Violencia de Género contra las Mujeres y el Acceso a la Justicia (2020). Observatorio de Violencia de Género contra las Mujeres y Acceso a la Justicia. San José, Costa Rica: Poder Judicial. Recuperado de: https://observatoriodegenero.poder-judicial.go.cr/

Oficina de Naciones Unidas contra la Droga y el Delito (2014). Informe Mundial sobre las Drogas 2014. Viena, Austria: Oficina de Naciones Unidas contra la Droga y el Delito. Recuperado de https://www.unodc.org/documents/wdr2014/V1403603_spanish.pdf 
ONU MUJERES (2015). Un marco de apoyo a la prevención de la violencia contra la mujer. Nueva York, Estados Unidos: Oficina Regional para las Américas y el Caribe de la Entidad de las Naciones Unidas para la Igualdad de Género y el Empoderamiento de las Mujeres (ONU Mujeres).

Pereira, S. (2012). Violencia contra las mujeres en la relación de pareja: Diagnóstico realizado en el Juzgado Contra la Violencia Doméstica de Cartago para un abordaje integral en el Poder Judicial de la violencia intrafamiliar desde la perspectiva de género (Tesis de maestría). Universidad de Costa Rica, San José, Costa Rica.

Piedra, M. y Esquivel, D. (2012). Seguridad Ciudadana para las Mujeres: una propuesta de política pública con perspectiva de género. San José, Costa Rica: Fundación Friederich Ebert.

Rainero, L.; Rodigou, M. y Pérez, S. (2006). Herramientas para la promoción de ciudades seguras desde la perspectiva de género. Córdoba, Argentina: Centro de Intercambio y Servicios Cono Sur Argentina (CICSA) y UNIFEM.

Rubin, G. (1986). El tráfico de mujeres: notas sobre la "economía política" del sexo. Nueva Antropología. 3 (30), 95-145.

Russell, D. y Harmes, R. (2006). Feminicidio: una perspectiva global (Russel, D. y Harmes, R., Eds.) México D.F., México: Centro de Investigaciones Interdisciplinarias en Ciencias y Humanidades, Universidad Nacional Autónoma de México.

Red Mujer y Hábitat en América Latina (2018). Construyendo ciudades seguras. Experiencias de redes de mujeres en América Latina (Red Mujer y Hábitat en América Latina, Ed.). Santiago, Chile: QP Ediciones.

Sagot, M. (1995a, Marzo). Violencia contra las mujeres: el continium de la muerte [Ponencia]. En: En Memoria. Seminario sobre Sensibilización de Género, Leyes y Políticas Relacionadas con las Mujeres. San José, Costa Rica. Instituto de Investigaciones Jurídicas, Universidad de Costa Rica.

Sagot, M. (1995b). Socialización de género, violencia y femicidio. Reflexiones. $41(1), 17-26$

Sagot M. y Carcedo A. (2000). Femicidio en Costa Rica 1990-1999. San José, Costa Rica: Organización Panamericana de la Salud.

Saltzman, J. (1992). Equidad y género. Valencia, España: Ediciones Cátedra e Instituto de la Mujer, Universitat de Valencia.

Seligman, M. (1975). Helplessness: on depression, development and death. San Francisco, Estados Unidos: Freeman. 
Solyszko, I. (2013). Femicidio y feminicidio: avances para nombrar la expresión letal de la violencia de género contra las mujeres. Géneros. 20 (13), 23-41.

Toledo, P. (2009). Feminicidio. México D.F., México: Oficina en México del Alto Comisionado de las Naciones Unidas para los Derechos Humanos.

UNODOC (2019). Global Study on Homicide: gender-related killing of women and girls. Viena, Austria: Oficina de Naciones Unidas sobre Drogas y Crimen.

Valenzuela, J.M. (2012). Sed de mal. Feminicidio, jóvenes y exclusión social. Nuevo León, México: Colegio de la Frontera Norte y Universidad Autónoma de Nuevo León.

Vargas, V. (2007). Programa Regional: Ciudades sin Violencia hacia las Mujeres Ciudades Seguras para Todas y Todos. Córdoba, Argentina: Red Mujer y Hábitat en América Latina y el Caribe y UNIFEM.

Walker, L. (1989). Terrifying love. Why battered women kill and how society responds. Nueva York, Estados Unidos: Harper Perennial.

Wu, S. (2012). Femicidio, un indicador de violencia social hacia la mujer. Medicina Legal de Costa Rica. 29 (1), 79-82. 